\title{
KRITERIA VITALITAS BAHASA TALONDO
}

Vitality Criteria of Talondo Language

\author{
Buha Aritonang \\ Badan Pengembangan dan Pembinaan Bahasa \\ Pos-el: buhaaritonang@yahoo.co.id
}

\begin{abstract}
Abstrak
Penelitian ini dilaksanakan di Desa Talondo Kondo, Kecamatan Bonehau, Kabupaten Mamuju, Provinsi Sulawesi Barat dengan tujuan untuk menentukan kriteria vitalitas bahasa Talondo. Metode pengumpulan data dilakukan dengan penelitian lapangan dan pustaka. Penelitian lapangan dilakukan untuk memperoleh data primer, sedangkan penelitian pustaka untuk memperoleh data sekunder. Sumber data dalam penelitian ini adalah 81 responden penutur bahasa Talondo. Data diperoleh dari hasil pengamatan dan kuesioner. Untuk menentukan kriteria vitalitas bahasa Talondo digunakan model skala Likert dan indeks dengan uji compare mean. Hasil perhitungan kelompok subindeks dengan karakteristik responden (jenis kelamin, kelompok usia, jenjang pendidikan, dan jenis pekerjaan) menunjukkan bahwa bahwa vitalitas bahasa Talondo masuk kriteria mengalami kemunduran. Hal itu disebabkan karena nilai penjumlahan dan pembagian rerata indeks total keempat variabel dengan variabel jenis kelamin, kelompok usia, jenjang pendidikan, dan jenis pekerjaan adalah 0,58. Nilai sebesar itu termasuk pada garis indeks $3-4$ berdasarkan visualisasinya pada diagram laba-laba.

Kata kunci: vitalitas, bahasa, indeks
\end{abstract}

\begin{abstract}
Abstrct
This research was conducted in the village of Talondo Kondo, District Bonehau, Mamuju, West Sulawesi province with the aim to determine the vitality of the Talondo languages criteria. The methods of the research was done by doing the field research and the literature study.A fieldwork was conducted to obtain primary data while the library research obtaining secondary data. The sources of data in this study were 81 respondents from Talondo language native speakers. The datas are obtained from observations and questionnaires. To determine the vitality of Talondo language criteria the research used Likert scale models to test and compare the mean index of vitality. The calculation result of subindex groups with respondent characteristics (based on gender, age group, education level, and occupation) showed that the vitality of a Talondo language was setbacks. Because the average value addition and division of the total index of the four variables with the variables gender, age group, education level, and type of work is 0.58. The range value of its included in the index line 3-4 based on visualization in a spider diagram.
\end{abstract}

Keywords: vitality, language, index 


\section{PENDAHULUAN}

Kehakikatan bahasa dapat mengungkapkan cara pandang suatu masyarakat tentang sesuatu dan melalui bahasa dapat diketahui aturan, tradisi, dan kepercayaan sebuah kelompok etnik (Dixon, 1997:135). Bahasa juga lahir dan hidup bersama masyarakatnya dan merupakan milik manusia yang paling utama. Sementara itu, antarindividu atau antarmasyarakat tidak dapat berkomunikasi tanpa bahasa sebagai media komunikasi karena hakikat bahasa tidak lepas dari individu, kelompok individu, dan masyarakat yang memilikinya. Secara sosial dapat dikatakan bahwa bahasa itu terus-menerus memahami fungsi sosialnya di segala bidang sebagai wadah perilaku dan aktivitas masyarakat di samping fungsinya sebagai alat komunikasi, yakni bidang sosial, ekonomi, politik, kedokteran, perdagangan, teknologi, sains, komunikasi dan transportasi. (Sumarsono dan Partana, 2004).

Jika dicermati keberadaan bahasa di Indonesia, bahasa daerah di Indonesia cukup beragam. Keberaman itu didasarkan keanekaan suku sehingga masyarakat Indonesia tergolong masyarakat multilingual. Bahasa daerah setiap suku menjadi bagian dari tiap orang dalam satu suku. Namun, kemampuan mewariskannya kepada generasi selanjutnya sangat berperan untuk kebertahan bahasa itu. Jika peran itu selalu diwujudkan, dimungkinkan akan terjadi bahwa anak-anak (generasi kedua) akan menjadi pengguna bahasa yang aktif karena mereka tetap konsisten menggunakan bahasa daerahnya. Agar hal ini tetap konsisten terjadi, peran orang tua cukup dominan sebagai pewaris bahasa sukunya kepada anak-anaknya sehingga bahasa sukunya tetap bertahan. Jika itu tidak diwariskan, bahasa-bahasa daerah dimungkinkan dapat berubah mengikuti sikap bahasa yang berubah sehingga dapat mengakibatkan pemertahanan, pergeseran bahasa (language shift), perubahan bahasa (language change), kepunahan, atau kematian bahasa. Sehubungan dengan itu, vitalitas bahasa daerah terikat dengan upaya penyelamatan, pemeliharaan, pembinaan, dan pengembangan bahasa. Oleh karena itu, penggalian, pencatatan, dan penelitian suatu bahasa daerah perlu dilaksanakan untuk mengetahui vitalitas suatu bahasa apakah masih tetap terjaga. Aktivitas demikian sangat bermanfaat bagi masyarakat penuturnya, kepentingan kebijakan, dan perencanaan bahasa secara nasional.

Grimes (2001) memperkirakan fenomena kepunahan bahasa pada masa yang akan datang, yaitu akan terjadi (i) penurunan drastis jumlah penutur aktif secara drastis, (ii) ranah penggunaan bahasa semakin berkurang, (iii) pengabaian atau pengenyahan bahasa ibu oleh penutur usia muda, (iv) usaha memelihara identitas etnik tanpa menggunakan bahasa ibu, (v) 
penutur generasi terakhir tidak mahir lagi menggunakan bahasa ibu (penguasaan pasif, understanding without speaking), dan (vi) contoh-contoh mengenai semakin punahnya dialekdialek satu bahasa, keterancaman bahasa kreol, dan bahasa sandi. Jika fenomena seperti itu benar-benar terjadi, tidak menutup kemungkinan akan banyak bahasa-bahasa minoritas di Indonesia yang akan mengalami kepunahan. Ditekankan juga bahwa sebab utama kepunahan bahasa adalah karena para orang tua tidak lagi mengajarkan bahasa ibu kepada anak-anaknya dan tidak lagi secara aktif menggunakannya di lingkungan rumah tangga dalam berbagai ranah komunikasi. Di samping itu, pergeseran bahasa dimungkinkan untuk mempengaruhi vitalias bahasa. Grimes (2002) mengutarakan beberapa faktor yang menyebabkan terjadinya pergeseran bahasa, yaitu (i) orang-orang tua yang memaksa anak-anaknya untuk mempelajari bahasa yang dianggap bergengsi, dengan pemikiran bahwa anak hanya mampu belajar satu bahasa dengan baik; (ii) penggunaan bahasa kedua sebagai bahasa pengantar di sekolahsekolah; (iii) kebijakan bahasa nasional yang cenderung menyebabkan sebagian penutur memilih menggunakan bahasa nasional sebagai bahasa ibu; dan (iv) industrialisasi, perubahan ekonomi, dan pemerintahan.

Faktor-faktor penyebab kepunahan bahasa itu tadi tentu terkait dengan sikap dan pemertahanan bahasa (language maintenance) masyarakat tuturnya. Jika pilihan untuk tidak menggunakan dan kebiasaan orang tua untuk tidak mentransmisikan bahasa ibu kepada anakanaknya lemah, pergerakan ke arah kepunahan akan lebih cepat. Bahasa dalam satu pergantian generasi atau mungkin 25 tahun akan punah atau mungkin lebih cepat akan punah. Sebaliknya, bahasa-bahasa yang penuturnya memiliki pemertahanan bahasa yang kuat memiliki vitalitas bahasa yang kuat. Ibrahim (2008) dengan hipotesis sosiolinguistik yang terkait dengan kecepatan kepunahan bahasa antargenerasi penutur menyatakan bahwa jika satu bahasa hanya digunakan oleh penutur yang berusia 25 tahun ke atas dan usia di bawahnya tidak lagi menggunakannya, 75 tahun ke depan-tiga generasi-bahasa itu akan terancam punah. Jika satu bahasa hanya digunakan secara aktif oleh penutur berusia 50 tahun ke atas dan usia di bawahnya tidak lagi menggunakannya, kemungkinan 50 tahun ke depandua generasi-bahasa itu akan punah. Jika satu bahasa secara aktif hanya digunakan oleh penutur yang berusia 75 tahun ke atas dan penutur berusia di bawahnya tidak lagi mahir menggunakannya, terutama dalam ranah keluarga, kemungkinan 25 tahun ke depan-satu generasi - bahasa itu akan (terancam) punah. Hipotesis itu tadi lebih spesifik lagi dirumuskan bahwa semakin muda usia penutur setiap bahasa tentu tidak lagi mahir menggunakan bahasa ibu dalam pergaulan sehari-hari sehingga bahasa itu semakin cepat mengalami kepunahan. Gerak ke arah kepunahan akan lebih cepat lagi apabila disertai dengan semakin berkurangnya 
cakupan dan jumlah ranah penggunaan bahasa dalam komunikasi sehari-hari atau semakin meluasnya ketiadaan penggunaan bahasa dalam sejumlah ranah, terutama ranah keluarga.

Bahasa Talondo sebagai salah satu bahasa daerah di Indonesia tergolong berpenutur yang tidak begitu banyak. Fakta demikian tentu bertentangan dengan pandangan Coulmas (1997:276). Menurut Coulmas, walaupun secara kuantitas jumlah penutur sebuah bahasa kecil, hal tersebut tidak selalu menjadi indikator keminoritasan karena ada pula bahasa yang meskipun jumlah penuturnya kecil, tetapi loyalitas mereka terhadap bahasanya cukup kuat sehingga terhindah dari ancaman kepunahan bahasa. Pandangan itu tadi sangat tidak tepat dianalogikan terhadap bahasa Talondo. Walapun demikian, bahasa Talondo yang dituturkan masyarakat Talondo di Desa Talondo Kondo, Kecamatan Bonehau, Kabupaten Mamuju, Provinsi Sulawesi Barat masih perlu diungkap kriteria vitalitasnya. Pemilihan bahasa itu sebagai objek kajian dilandasi pertimbangan bahwa bahasa Indonesia telah mendesak esksistensinya apalagi wilayah pakai bahasa Talondo telah tergerus akibat bersinggungan dengan bahasa masyarakat pendatang (transmigran). Sehubungan dengan itu, masalah yang dianalisis sesuai dengan latar belakang masalah tadi adalah karakteristik responden dan penetapan kriteria vitalitas bahasa Talondo berdasarkan hubungan nilai rerata indeks dengan karakteristik responden. Sesuai dengan masalah itu tadi, penelitian ini bertujuan untuk mengetahui karakteristik responden dan kriteria vitalitas bahasa Talondo berdasarkan hubungan nilai rerata indeks dengan karakteristik responden. Dengan mengacu pada tujuan tersebut, penelitian ini bermanfaat untuk dijadikan sebagai sumber informasi tentang daya hidup bahasa Talondo dan dapat juga dijadikan sebagai bahan pemetaan vitalitas bahasabahasa daerah, sedangkan manfaat akademisnya dapat dijadikan sebagai sumber pendalaman ilmu linguistik, khususnya perencanaan dan kebijakan bahasa terhadap bahasa-bahasa minoritas. Agar masalah dan tujuan penelitian tercapai sesuai dengan yang diharapkan, ruang lingkup penelitian ini dibatasi pada penetapan kriteria vitalitas bahasa Talondo berdasarkan hubungan nilai rerata indeks dengan karakteristik responden.

\section{LANDASAN TEORI}

Dalam rangka penelitian kriteria vitalitas kebahasaan Talondo, diupayakan untuk mencari sebanyak mungkin tulisan atau buku yang berkaitan dengan kajian itu. Akan tetapi, hasil studi pustaka tentang bahasa Talondo cukup sangat terbatas. SIL (2006) mengidentifikasi bahasa Talondo sebagai salah satu bahasa di Pulau Sulawesi.

Teori yang digunakan dalam penelitian ini adalah teori sosiolinguistik karena (i) menempatkan kedudukan bahasa dalam hubungannya dengan pemakaiannya di dalam 
masyarakat dan (ii) merupakan ilmu antardisiplin, yaitu antara sosiologi dan linguistik yang merupakan dua bidang ilmu empiris yang mempunyai kaitan sangat erat. Ini berarti bahwa sosiolinguistik memandang bahasa pertama-tama sebagai sistem sosial dan sistem komunikasi, serta bagian dari masyarakat dan kebudayaan tertentu, sedangkan pemakaian bahasa adalah bentuk interaksi sosial yang terjadi di dalam situasi-situasi yang kongkrit (Suwito, 1983).

Selain teori ini, digunakan juga teori vitalitas bahasa. Menurut Fishman dalam Ibrahim (2008), vitalitas bahasa atau keterpakaian bahasa adalah pemakaian sistem linguistik oleh suatu masyarakat penutur asli yang tidak terisolasi. Jadi, vitalitas mempersoalkan apakah sistem linguistik tersebut masih memiliki penutur asli yang menggunakan atau tidak. Teori kriteria vitalitas bahasa yang diterapkan mencakup pada (1) sangat kritis, (2) sangat terancam, (3) terancam, (4) mengalami kemunduran, (5) stabil, mantap, tetapi berpotensi mengalami kemunduran dan (6) aman (Grimes, 2002:13). Sangat kritis (critically endangered) berarti hanya sisa sedikit sekali penutur karena semua berumur 70 tahun ke atas dan termasuk berusia kakek-nenek buyut. Sangat terancam (serserely endangered) berarti semua penutur berumur 40 tahun ke atas dan termasuk berusia kakek-nenek. Terancam (endangered) berarti semua penuturnya berusia 20 tahun ke atas dan termasuk berusia orang tua. Mengalami kemunduran (eroding) berarti sebagian penutur terdiri atas anak-anak dan kaum tua. Kondisi stabil dan mantap, tetapi terancam punah (stable but threatened) berarti semua anak-anak dan kaum tua menggunakannya, tetapi jumlah penutur sedikit. Aman (safe) berarti tidak terancam punah karena bahasa ini diharapkan dipelajari oleh semua anak dan semua orang dalam kelompok etnis tersebut (lihat Tabel 2 dan Gambar 1).

Wurm (1998) dalam Crystal (2000) mengklasifikasikan kondisi kesehatan bahasa dalam berapa tahap, yaitu (1) potentially endangered language (bahasa-bahasa yang dianggap berpotensi terancam punah) adalah bahasa yang secara sosial dan ekonomi tergolong minoritas serta mendapat tekanan yang cukup besar dari bahasa mayoritas dan jarang menggunakan bahasa daerah; (ii) endangered language (bahasa-bahasa yang terancam punah) adalah bahasa yang tidak mempunyai lagi generasi muda yang dapat berbahasa daerah; penutur yang fasih hanya kelompok generasi menengah (dewasa); (iii) seriously endangered language (bahasa-bahasa yang dianggap sangat terancam punah) adalah bahasa yang hanya berpenutur generasi tua berusia di atas 50 tahun; (iv) moribond language (bahasa-bahasa yang dianggap sekarat) adalah bahasa yang dituturkan oleh beberapa orang sepuh, yaitu sekitar 70 tahun ke atas; (v) extinct language (bahasa-bahasa yang dianggap punah) adalah bahasa yang 
penuturnya tinggal satu orang sehingga tidak ada teman berkomunikasi dalam bahasa itu apalagi jika sudah tidak ada penuturnya lagi.

Jika vitalitas bahasa dikaitkan dengan kondisi bahasa daerah, Stewart dalam Fishman, ed. (1968:536) menyatakan bahwa kepunahan suatu bahasa dapat disebabkan (i) ketidaksetiaan penutur terhadap bahasanya (sikap terhadap bahasanya), (ii) jumlah penutur yang sedikit, (iii) penutur yang terpencar-pencar yang mengakibatkan terpolarisasinya penggunaan bahasa, (iv) rendahnya status sosial penuturnya, (v) status bahasa yang mayoritas merupakan bahasa minor, (vi) perubahan komposisi penduduk, dan (vii) transformasi sosial budaya. Di antara penyebab kepunahan bahasa tersebut, ketidaksetiaan penutur terhadap bahasanya dan jumlah penutur yang sedikit merupakan faktor yang sangat dominan mempengaruhi kepunahan bahasa. Sementara itu, penutur yang terpencar dan rendahnya status sosial penuturnya memperlemah peran sosial bahasa itu. Karena peran sosialnya rendah, daya tahan bahasa untuk hidup juga lemah, apalagi jika status bahasa itu adalah bahasa minor. Hal yang juga dapat memengaruhi kepunahan bahasa adalah perubahan komposisi penduduk.

\section{METODE PENELITIAN}

Objek penelitian ini adalah bahasa Talondo yang lokasi tuturannya di Desa Talondo Kondo, Kecamatan Bonehau, Kabupaten Mamuju, Provinsi Sulawesi Barat. Penelitian dilaksanakan tahun 2014. Alasan pemilihan lokasi penelitian ini didasarkan atas pertimbangan bahwa bahasa itu diprediksi akan mengalami kepunahan dan kepustakan bahasa itu pun tergolong langka. Peneliti berasumsi juga bahwa desa itu berdekatan dengan wilayah transmigrasi.

Penelitian ini termasuk penelitian terapan, yaitu penelitian yang diarahkan untuk mendapatkan informasi yang dapat digunakan untuk memecahkan masalah. Pendekatannya menerapkan penelitian survei, yaitu penelitian yang dilakukan pada populasi relatif besar, tetapi sampel diambil dari populasi. Pemilihan sampel menggunakan teknik purposive sampling, yaitu pengambilan elemen-elemen yang dimasukkan dalam sampel dilakukan dengan sengaja dengan catatan bahwa sampel tersebut representatif atau mewakili populasi yang diteliti sehingga sampel penelitian ini ditetapkan 81 responden.

Jenis data penelitian ini terdiri dari data primer dan data sekunder. Data primer adalah data yang diperoleh langsung dari sumbernya dan dicatat oleh peneliti melalui daftar tanyaan dalam kuesioner. Data sekunder adalah data yang secara tidak langsung diperoleh dari sumbernya, tetapi melalui pihak kedua dengan menjaring data dari aparat desa. Dengan 
demikian, jenis data penelitian tergolong data kualitatif yang diangkakan atau dikuantitatifkan.

Alat ukur yang digunakan untuk menganalisis kriteria vitalitas bahasa Talondo adalah model skala Likert dan indeks dengan uji compare mean dengan menggunakan aplikasi SPSS 19. Skala Likert ini berisikan seperangkat pernyataan yang harus dijawab oleh responden untuk menggiring kecenderungan persepsi responden tentang (a) mobilitas informan pada posisi relatif kota-desa apakah (i) sering dengan bobot 1, jarang 2, tidak pernah 3;' (ii) tinggi dengan bobot 1, sedang 2, rendah 3; (iii) dekat dengan bobot 1, sedang (2), jauh 3; (iv) sulit dengan bobot 1, sedang 2, mudah 3, dan (vi) sedikit 1, agak banyak 2, banyak 3; (b) kedwibahasaan apakah (i) bahasa Indonesia, bahasa Melayu ..., bahasa ...; (ii) sangat baik dengan bobot 1, baik 2, tidak baik 3; (iii) tidak ada dengan bobot 1, bahasa Indonesia 2, bahasa daerah 3, yaitu ..., bahasa asing 4, yaitu ...; (iv) tidak baik dengan bobot 1, sedang 2, baik 3; (v) orang tua dengan bobot 1, teman 2, belajar 3; (vi) bahasa ibu > bahasa lain dengan bobot 1, bahasa ibu = bahasa lain (2), bahasa ibu< bahasa lain; dan (vii) tidak menghargai dengan bobot 1, menghargai 2, sangat menghargai 3; (b) penggunaan bahasa dengan cakupan (1) antargenerasi; (2) ranah keluarga; (3) ranah transaksi; (4) ranah ekspresi tulis; (5) pengungkap ekspresi perasaan apakah sering dengan bobot 1, jarang 2, tidak pernah 3; (6) ranah keagamaan apakah ya dengan bobot 1 dan tidak (bahasa ....) 2; . (7) ranah pemerintahan apakah sulit dengan bobot 1, agak sulit 2, atau mudah 3 dan (ii) sering dengan bobot 1, jarang (2), atau tidak pernah 3; (8) ranah pendidikan apakah sangat setuju dengan bobot 1, setuju 2, ragu-ragu 3, tidak setuju 4, atau sangat tidak setuju 5; dan (d) sikap bahasa apakah sangat setuju dengan bobot 1, setuju 2, ragu-ragu 3, tidak setuju 4, atau sangat tidak setuju 5. Sementara itu, indeks dimaksud di sini adalah ukuran gabungan suatu variabel agar diperoleh ukuran yang lebih lengkap dan tepat. Indeks ditentukan atas beberapa pertanyaan yang digabungkan menjadi satu atau akumulasi skor untuk tiap pertanyaan. Misalnya, untuk mengukur mobilitas informan pada posisi relatif kota-desa digunakan indeks nilai mobilitas informan pada posisi relatif kota-desa yang terdiri atas beberapa pertanyaan. Berdasarkan hal itu, diperoleh hasil perhitungan kelompok subindeks dengan karakteristik responden (jenis kelamin, kelompok usia, jenjang pendidikan, dan jenis pekerjaan) untuk menentukan kriteria bahasa Talondo. 


\section{PEMBAHASAN}

\section{Karakteristik Reponden}

Deskripsi karakteristik responden meliputi (i) jenis kelamin, (ii) kelompok usia, (iii) suku bangsa informan, (iv) suku bangsa istri, (v) suku bangsa suami, (vi) suku bangsa ayah, (vii) suku bangsa ibu, (viii) suku bangsa kakek, (ix) suku bangsa nenek, (x) jenjang pendidikan, (xi) jenis pekerjaan, (xii) tempat tinggal sebelum menikah, (xiii) tempat tinggal setelah menikah, (xiv) lama tinggal, dan (xv) nama bahasa ibu, seperti yang diperlihatkan pada tabel berikut.

Tabel 1.

Karakteristik Responden

\begin{tabular}{|c|c|c|c|c|c|}
\hline \multirow{2}{*}{ No. } & \multirow{2}{*}{\multicolumn{2}{|c|}{ Karakteristik }} & & \multicolumn{2}{|c|}{ Frekuensi dan Persentase } \\
\hline & & & & $\mathbf{F}$ & $\%$ \\
\hline \multirow{3}{*}{1.} & \multirow{3}{*}{ Jenis kelamin } & Laki-Laki & & 39 & 48,1 \\
\hline & & Perempuan & & 42 & 51,9 \\
\hline & & & Total & 81 & 100 \\
\hline \multirow{4}{*}{2.} & \multirow{4}{*}{ Kelompok usia } & $<25$ tahun & & 28 & 34,6 \\
\hline & & 26--50 tahun & & 27 & 33,3 \\
\hline & & $>51$ tahun & & 26 & 32,1 \\
\hline & & & Total & 81 & 100 \\
\hline \multirow{2}{*}{3.} & \multirow{2}{*}{ Suku bangsa informan } & Talondo & & 81 & 100 \\
\hline & & & Total & 81 & 100 \\
\hline \multirow{3}{*}{4.} & \multirow{3}{*}{ Suku bangsa istri } & Tidak menjawab & & 54 & 66,7 \\
\hline & & Talondo & & 27 & 33,3 \\
\hline & & & Total & 81 & 100 \\
\hline \multirow{4}{*}{5.} & \multirow{4}{*}{ Suku bangsa suami } & Tidak menjawab & & 55 & 67,9 \\
\hline & & Talondo & & 25 & 30,9 \\
\hline & & Luwu/Palopo & & 1 & 1,2 \\
\hline & & & Total & 81 & 100 \\
\hline \multirow{3}{*}{6.} & \multirow{3}{*}{ Suku bangsa ayah } & Tidak menjawab & & 4 & 4,9 \\
\hline & & Talondo & & 77 & 95,1 \\
\hline & & & Total & 81 & 100 \\
\hline \multirow{4}{*}{7.} & \multirow{4}{*}{ Suku bangsa ibu } & Tidak menjawab & & 4 & 4,9 \\
\hline & & Talondo & & 76 & 93,8 \\
\hline & & Passodanan & & 1 & 1,2 \\
\hline & & & Total & 81 & 100 \\
\hline \multirow{3}{*}{8.} & \multirow{3}{*}{ Suku bangsa kakek } & Tidak menjawab & & 4 & 4,9 \\
\hline & & Talondo & & 77 & 95,1 \\
\hline & & & Total & 81 & 100 \\
\hline \multirow{4}{*}{9.} & \multirow{4}{*}{ Suku bangsa nenek } & Tidak menjawab & & 4 & 4,9 \\
\hline & & Talondo & & 75 & 92,6 \\
\hline & & Mandar & & 2 & 2,5 \\
\hline & & & Total & 81 & 100 \\
\hline \multirow{5}{*}{10.} & \multirow{5}{*}{ Jenjang pendidikan } & Tidak menjawab & & 2 & 2,5 \\
\hline & & Rendah & & 29 & 35,8 \\
\hline & & Menengah & & 46 & 56,8 \\
\hline & & Tinggi & & 4 & 4,9 \\
\hline & & & Total & 81 & 100 \\
\hline & & Tidak menjawab & & 3 & 3,7 \\
\hline & & Rendah & & 55 & 67,9 \\
\hline 11. & Jenis pekerjaan & Menengah & & 19 & 23,5 \\
\hline & & Tinggi & & 4 & 4,9 \\
\hline & & & Total & 81 & 100 \\
\hline & & Talondo Kondo & & 81 & 100 \\
\hline 12. & Tempat tınggal sebelum menıkah & & Total & 81 & 100 \\
\hline 13 & Temnat tinogal setelah menikah & Talondo Kondo & & 81 & 100 \\
\hline 13. & lempat tinggal seterah menikah & & Total & 81 & 100 \\
\hline 14. & Lama tinggal & Tidak menjawab & & 1 & 1,2 \\
\hline
\end{tabular}




\begin{tabular}{lllll}
\hline & & & 80 & 98,8 \\
\cline { 3 - 5 } & & Total & $\mathbf{8 1}$ & $\mathbf{1 0 0}$ \\
\hline \multirow{2}{*}{ 15. Nama bahasa ibu } & Bahasa Talondo & & 81 & 100 \\
\cline { 3 - 5 } & & Total & $\mathbf{8 1}$ & $\mathbf{1 0 0}$ \\
\hline
\end{tabular}

Sumber: Data Diolah dari Keluaran Tabel Frekuensi dengan SPSS 19

Karakteristik responden pada Tabel 1 menunjukkan bahwa frekuensi dan persentase responden (i) jenis kelamin laki adalah 39 (48,1\%) dan perempuan 42 (51,9\%); (ii) kelompok usia responden dengan usia (a) < 25 tahun sebanyak 28 (34,6\%), (b) 26--50 tahun 27 $(33,3 \%)$, dan > 51 tahun $26(32,1 \%)$; (iii) suku bangsa responden adalah suku bangsa Talondo sebanyak 81 (100\%); (iv) suku bangsa istri responden adalah suku bangsa Talondo sebanyak $27(33,3 \%)$ dan tidak menjawab sebanyak 54 (66,7\%); (v) suku bangsa suami responden terdiri dari suku bangsa (a) Talondo sebanyak 25 (30,9\%), (b) Luwu/Palopo 1 $(1,2 \%)$, dan 55 (67,9\%) di antaranya tidak menjawab; (vi) suku bangsa ayah responden adalah Talondo sebanyak 82 (100\%); (vii) suku bangsa ibu responden terdiri dari suku bangsa (a) Talondo sebanyak 76 (93,8\%), (b) Passodanan 1 (1,2\%), dan (c) 4 (4,9\%) di antaranya tidak menjawab; (viii) suku bangsa kakek responden adalah Talondo sebanyak 77 (95,1\%) dan 4 $(4,9 \%)$ di antaranya tidak menjawab; (ix) suku bangsa nenek responden terdiri dari suku bangsa (a) Talondo sebanyak 75 (92,6\%), (b) Mandar 2 (2,5\%), dan (c) 4 (4,9\%) di antaranya tidak menjawab; (x) jenjang pendidikan responden terdiri dari pendidikan (a) rendah 29 $(35,8 \%)$, (b) menengah $46(56,8 \%)$, (c) tinggi $4(4,9 \%)$, dan $2(2,5 \%)$ di antaranya tidak menjawab; (xi) jenis pekerjaan responden terdiri jenis pekerjaan (a) rendah 55 (67,9\%), (b) menengah 19 (23,5\%), (c) tinggi 4 (4,9\%), dan (d) tidak menjawab 3 (3,7\%); (xii) tempat tinggal responden sebelum menikah hanya di Desa Talondo Kondo sebanyak 81 (1005); (xiii) tempat tinggal responden setelah menikah meliputi wilayah di Desa Talondo Kondo sebanyak 81 (1005); (xiv) lama tinggal atau berdomisili responden di Desa Talondo Kondo > 10 tahun sebanyak 81 (100\%); dan (xv) responden berbahasa ibu bahasa Talondo sebanyak 81 (100\%).

\section{Kriteria Vitalitas Bahasa Talondo}

Indentifikasi kriteria vitalitas bahasa Talondo dapat ditentukan dengan hasil perhitungan kelompok subindeks dengan keempat variabel karakteristik responden, yaitu jenis kelamin, kelompok usia, jenjang pendidikan, dan jenis pekerjaan. Dari hasil perhitungan itu akan didapat nilai masing-masing subindeks, indeks total, dan rata-rata indeks total. Adapun subindeks yang dimaksud adalah (1) Imob (indeks mobilitas informan pada posisi relatif kotadesa), (2) Ibil (indeks kedwibahasaan informan), (3) Itrn (indeks penggunaan bahasa antargenerasi), (4) Ikel (penggunaan bahasa menurut ranah keluarga), (5) Isaksi (indeks penggunaan bahasa menurut ranah transaksi), (6) Itulis (indeks penggunaan bahasa informan 
pada ranah/ekspresi tulis), (7) Irasa (indeks penggunaan bahasa informan untuk mengungkapkan ekspresi perasaan), (8) Iagm (indeks penggunaan bahasa pada ranah keagamaan), (9) Ipem (indeks penggunaan bahasa informan pada ranah pemerintahan), (10) Ipend (indeks penggunaan bahasa informan pada ranah pendidikan), dan (11) Iskp (indeks sikap bahasa). Nilai kelompok subindeks dengan variabel jenis kelamin, kelompok usia, jenjang pendidikan, dan jenis pekerjaan divisualisasi dengan diagram jaring laba-laba (spider diagram) (lihat Gambar 1) dengan menampilkan nilai rata-rata subindeks dalam bentuk grafik dua dimensi yang kemudian diinterpretasikan sesuai dengan kriteria vitalitas bahasa Grimes (2001) dalam Mahsun (2006) dengan kisaran 0 - 1 (lihat Tabel 2).

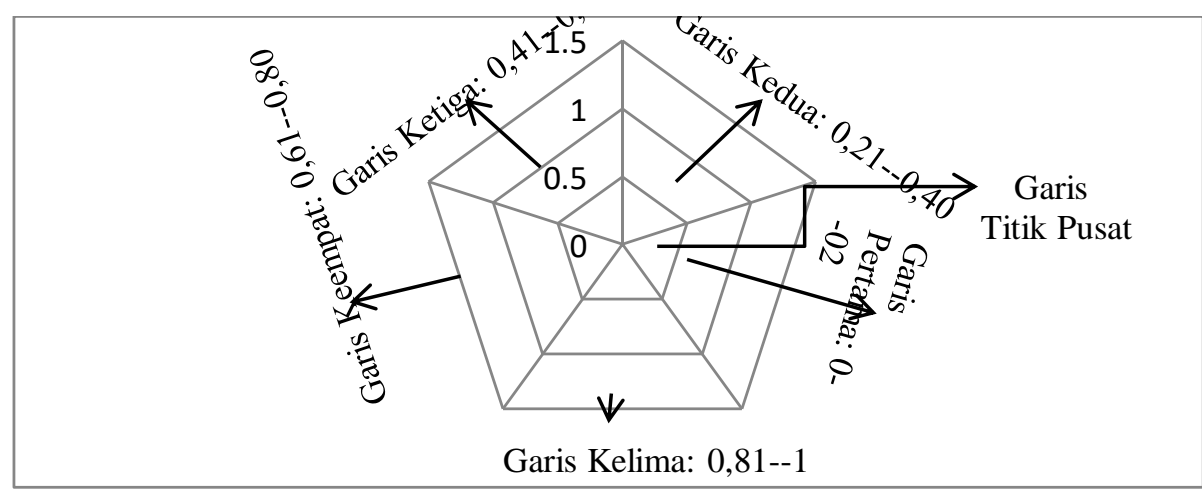

Gambar 1.

Interpretasi Kriteria Vitalitas Bahasa

Berdasarkan Visualisasi Diagram Jaring Laba-laba

Tabel 2. Kriteria Vitalitas Bahasa

\begin{tabular}{|c|c|c|c|}
\hline \multirow[t]{2}{*}{ No. } & \multirow[t]{2}{*}{ Kriteria Vitalitas Bahasa (Grimes, 2001)* } & \multicolumn{2}{|c|}{$\begin{array}{c}\text { Angka dan Garis Indeks } \\
\text { Diagram Jaring Laba-Laba** }\end{array}$} \\
\hline & & Angka Indeks & Garis Indeks \\
\hline 1. & Sangat kritis dan terancam & $0,0-0,20$ & $1--2$ \\
\hline 2. & Terancam & $0,21-0,40$ & $2-3$ \\
\hline 3. & Mengalami kemunduran & $0,41-0,60$ & $3-4$ \\
\hline 4. & Stabil dan mantap, tetapi terancam punah & $0,61-0,80$ & $4-5$ \\
\hline 5. & Aman & $0,81-1$ & $5-6$ \\
\hline Sumber: & $\begin{array}{ll}* & \text { Grimes (2001) dalam Mahsun (2006) } \\
* * & \text { Konvensi peserta dan narasumber pada } \\
& \text { Tanggal 2-4 Desember } 2011 .\end{array}$ & "Konsinyasi Bahasa & Terancam Punah" di Hotel Amarsa, Ciawi, \\
\hline
\end{tabular}

Dengan visualiasi indeks pada diagram jaring laba-laba yang disesuaikan dengan kriteria vitalitas bahasa pada Tabel 2, tiga hal yang perlu diperhitungkan untuk menentukan vitalitas bahasa. Hal pertama adalah menentukan indeks total semua nilai rerata setiap subindeks dengan variabel (jenis kelamin, kelompok usia, jenjang pendidikan, atau jenis pekerjaan) (lihat 4.2.1 - 4.2.4). Hal kedua adalah indeks total untuk masing-masing subbagian variabel dijumlahkah setelah diketahui indeks total. Hasil penjumlahan indeks total dibagi dengan jumlah subbagian variabel jenis kelamin, kelompok usia, jenjang pendidikan, atau 
jenis pekerjaan sehingga dihasilkan rata-rata indeks total setiap variabel. Hal ketiga adalah nilai rata-rata indeks total setiap variabel dijumlahkah dan dibagi dengan jumlah variabel, yaitu variabel (jenis kelamin, kelompok usia, jenjang pendidikan, atau jenis pekerjaan) untuk menentukan vitalitas bahasa. Dengan demikian, dapat ditarik kesimpulan (i) apabila nilai ratarata indeks total setiap variabel terletak atau mendekati angka 1 pada garis kelima dari garis titik pusat diagram jaring laba-laba, vitalitas bahasa tergolong aman; (ii) apabila nilai ratarata indeks total setiap variabel terletak atau mendekati angka 0,8 atau 0,80 pada garis keempat dari garis titik pusat diagram jaring laba-laba, vitalitas bahasa tergolong stabil (mantap), tetapi terancam punah; dan (iii) apabila nilai rata-rata indeks total setiap variabel terletak atau mendekati angka 0,6 atau 060 pada garis ketiga dari garis titik pusat diagram jaring laba-laba, vitalitas bahasa tergolong mengalami kemunduran, (iv) apabila nilai rata-rata indeks total setiap variabel terletak atau mendekati angka 0,4 atau 0,40 pada garis kedua dari garis titik pusat diagram jaring laba-laba, vitalitas bahasa tergolong terancam, dan (v) apabila nilai rata-rata indeks total setiap variabel terletak atau mendekati angka 0,2 atau 0,20 pada garis pertama dari garis titik pusat diagram jaring laba-laba, vitalitas bahasa tergolong sangat terancam dan kritis.

\subsection{Jenis Kelamin}

Hubungan jenis kelamin yang terdiri dari dua subbagian (laki-laki dan perempuan) dikaitkan dengan semua subindeks (Imob, Ibil, Itrn, Ikel, Isaksi, Itulis, Irasa, Iagm, Ipem, Ipend, dan Isikap) dapat dijadikan sebagai penentu kriteria vitalitas bahasa Talondo. Hal itu mengacu pada besaran nilai rerata setiap subindeks berdasarkan variabel jenis kelamin pada Tabel 3 yang kemudian divisualisasi dalam bentuk diagram jaring laba-laba (lihat Gambar 2).

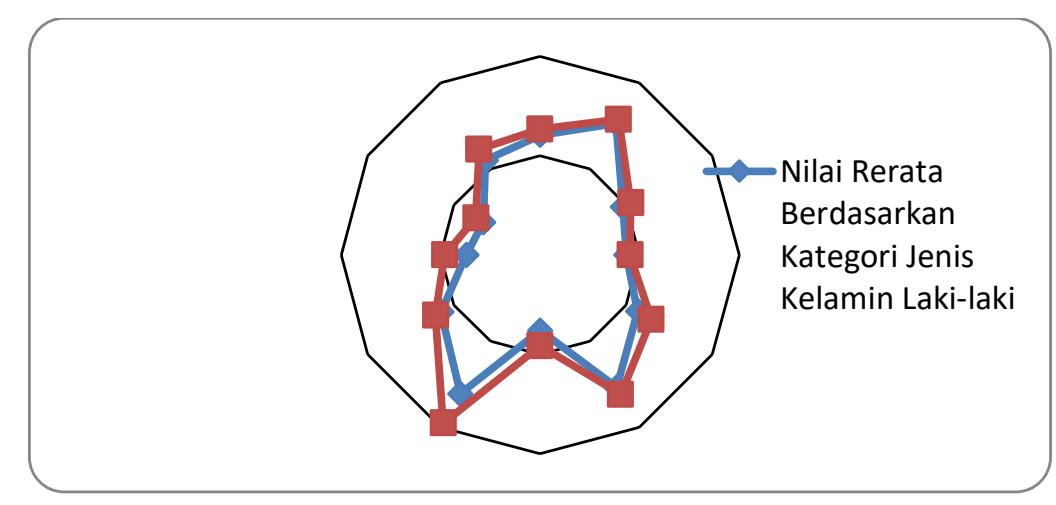

Gambar 2.

Rerata Antarindeks Berdasarkan Jenis Kelamin 
Tabel 3.

Perbandingan Rerata Antarindeks Berdasarkan Kategori Jenis Kelamin

\begin{tabular}{|c|c|c|}
\hline \multirow{2}{*}{ Jenis Indeks } & \multicolumn{2}{|c|}{ Nilai Rerata Berdasarkan Kategori Jenis Kelamin } \\
\hline & Laki-laki & Perempuan \\
\hline Imob & 0,60 & 0,63 \\
\hline Ibil & 0,76 & 0,79 \\
\hline Itrn & 0,48 & 0,53 \\
\hline Ikel & 0,43 & 0,45 \\
\hline Isaksi & 0,57 & 0,65 \\
\hline Itulis & 0,77 & 0,81 \\
\hline Irasa & 0,38 & 0,46 \\
\hline Iagm & 0,81 & 0,98 \\
\hline Ipem & 0,57 & 0,61 \\
\hline Ipend & 0,37 & 0,48 \\
\hline Isikap & 0,33 & 0,37 \\
\hline Itotal & $\mathbf{0 , 5 5}$ & $\mathbf{0 , 6 1}$ \\
\hline Rata-rata Itotal & \multicolumn{2}{|c|}{$0,55+0,61 / 2=0,58$} \\
\hline
\end{tabular}

Sumber: Data Diolah dari Keluaran Tabel Compare Means dengan SPSS 19

Perbandingan indeks total dan subindeks berdasarkan berdasarkan jenis kelamin (lakilaki dan perempuan) pada Tabel 3 menunjukkan pola yang relatif sama. Secara total terlihat bahwa indeks vitalitas bahasa Talondo, baik pada laki-laki maupun perempuan berada pada jaring/garis indeks ke- 3--4 dan 4--5 dengan nilai indeks 0,55 dan 0,61 sehingga kriteria vitalitas bahasa Talondo tergolong (i) mengalami kemunduran dan (ii) stabil dan mantap, tetapi terancam punah.

\subsection{Kelompok Usia}

Hubungkan variabel kelompok usia yang terdiri dari tiga subbagian $(<25$ tahun, $25-$ 50 tahun, dan > 51 tahun) dengan semua subindeks (Imob, Ibil, Itrn, Ikel, Isaksi, Itulis, Irasa, Iagm, Ipem, Ipend, dan Isikap) termasuk juga sebagai salah satu aspek yang dijadikan penentu kriteria vitalitas bahasa Talondo. Acuannya adalah besaran nilai rerata setiap subindeks berdasarkan variabel kelompok usia pada Tabel 4 yang kemudian divisualisasi dalam bentuk diagram jaring laba-laba (lihat Gambar 3). 


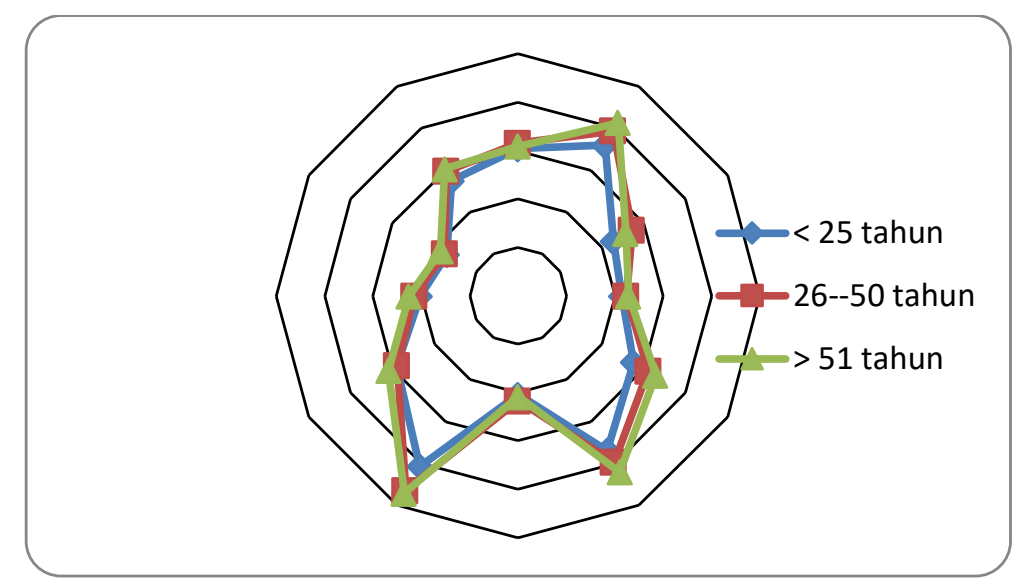

Gambar 3.

Rerata Antarindeks Berdasarkan Kelompok Usia

Tabel 4.

Perbandingan Rerata Antarindeks Berdasarkan Kelompok Usia

\begin{tabular}{|c|c|c|c|}
\hline \multirow{2}{*}{$\begin{array}{l}\text { Jenis } \\
\text { Indeks }\end{array}$} & \multicolumn{3}{|c|}{ Kelompok Usia } \\
\hline & $<25$ tahun & $25-50$ tahun & $>51$ tahun \\
\hline Imob & 0,61 & 0,63 & 0,62 \\
\hline Ibil & 0,72 & 0,79 & 0,83 \\
\hline Itrn & 0,45 & 0,54 & 0,51 \\
\hline Ikel & 0,43 & 0,45 & 0,46 \\
\hline Isaksi & 0,55 & 0,62 & 0,66 \\
\hline Itulis & 0,74 & 0,79 & 0,84 \\
\hline Irasa & 0,41 & 0,43 & 0,42 \\
\hline Iagm & 0,81 & 0,93 & 0,94 \\
\hline Ipem & 0,58 & 0,58 & 0,62 \\
\hline Ipend & 0,41 & 0,43 & 0,45 \\
\hline Iskp & 0,34 & 0,35 & 0,37 \\
\hline Itotal & $\mathbf{0 , 5 5}$ & 0,60 & 0,61 \\
\hline
\end{tabular}

Rata-rata Itotal $\quad 0,55+0,60+0,61 / 3=0,59$

Sumber: Data Diolah dari Keluaran Tabel Compare Means dengan SPSS 19

Perbandingan indeks total dan subindeks berdasarkan kelompok usia $(<25$ tahun, 25-50 tahun, > 51 tahun) pada Tabel 4 menunjukkan pola yang tidak sama. Secara indeks total terlihat bahwa indeks vitalitas bahasa Talondo untuk kelompok usia $<25$ tahun adalah 0,55, 25-50 tahun 0,60, dan > 50 tahun 0,61 dan berada pada jaring/garis indeks ke- 3--4 dan 4--5 sehingga vitalitas bahasa Talondo tergolong (i) mengalami kemunduran dan (ii) stabil dan mantap, tetapi terancam punah.

\subsection{Jenjang Pendidikan}

Semua hubungan subindeks dengan variabel jenjang pendidikan yang terdiri dari tiga subbagian (pendikan rendah, menengah, dan tinggi) termasuk juga sebagai salah satu aspek yang dijadikan penentu vitalitas bahasa Talondo. Acuannya adalah besaran nilai rerata setiap 
subindeks berdasarkan variabel jenjang pendidikan pada Tabel 5 yang kemudian divisualisasi dalam bentuk diagram jaring laba-laba (lihat Gambar 4).

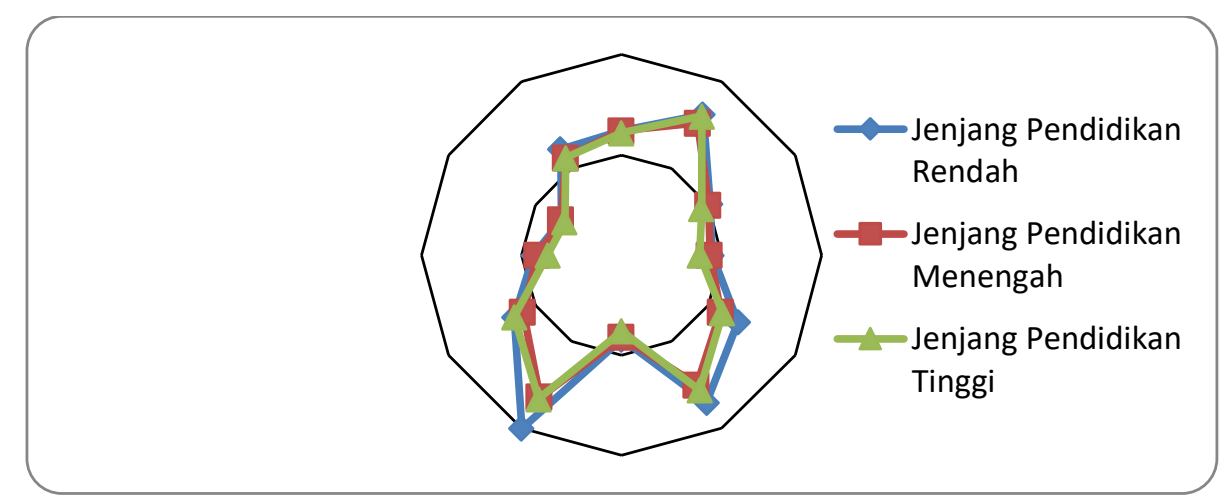

Gambar 4.

Rerata Antarindeks Berdasarkan Jenjang Pendidikan

Tabel 5.

Perbandingan Rerata Antarindeks

Berdasarkan Kategori Jenjang Pendidikan

\begin{tabular}{|c|c|c|c|}
\hline \multirow{2}{*}{$\begin{array}{l}\text { Jenis } \\
\text { Indeks }\end{array}$} & \multicolumn{3}{|c|}{ Jenjang Pendidikan } \\
\hline & Rendah & Menengah & Tinggi \\
\hline Imob & 0,62 & 0,62 & 0,61 \\
\hline Ibil & 0,81 & 0,76 & 0,80 \\
\hline Itrn & 0,51 & 0,50 & 0,46 \\
\hline Ikel & 0,45 & 0,44 & 0,39 \\
\hline Isaksi & 0,67 & 0,57 & 0,58 \\
\hline Itulis & 0,85 & 0,75 & 0,78 \\
\hline Irasa & 0,42 & 0,41 & 0,38 \\
\hline Iagm & 1 & 0,82 & 0,83 \\
\hline Ipem & 0,62 & 0,57 & 0,62 \\
\hline Ipend & 0,44 & 0,42 & 0,37 \\
\hline Iskp & 0,35 & 0,35 & 0,33 \\
\hline Itotal & $\mathbf{0 , 6 1}$ & 0,56 & 0,56 \\
\hline
\end{tabular}

Sumber: Data Diolah dari Keluaran Tabel Compare Means dengan SPSS 19

Perbandingan indeks total dan subindeks berdasarkan berdasarkan kelompok jenjang pendidikan (rendah, menengah, dan tinggi) pada Tabel 5 menunjukkan pola yang relatif sama. Secara total terlihat bahwa indeks vitalitas bahasa Talondo untuk kelompok yang berpendidikan menengah dan tinggi berada pada jaring/garis indeks ke- 4--5 dan 3--4 dengan nilai indeks total 0,61 untuk jenjang yang berpendidikan rendah dan 0,56 untuk yang berpendidikan menengah dan tinggi. Dengan demikian, kriteria vitalitas bahasa Talondo berdasarkan jenjang pendidikan diklasifikasikan menjadi dua, yaitu (i) mengalami kemunduran karena indeks total variabel dengan jenjang pendidikan menengah dan tinggi 0,56 dan (ii) stabil dan mantap, tetapi mengalami kemunduran karena indeks total variabel 
dengan jenjang pendidikan rendah 0,61. Nilai kedua indeks total keduanya berada pada garis ke- 3--4 dan 4--5.

\subsection{Jenis Pekerjaan}

Hubungkan variabel jenjang pekerjaan yang terdiri dari tiga subbagian (jenis pekerjaan rendah, menengah, dan tinggi) dengan semua subindeks (Imob, Ibil, Itrn, Ikel, Isaksi, Itulis, Irasa, Iagm, Ipem, Ipend, dan Isikap) menjadi salah satu aspek juga untuk menentukan vitalitas bahasa Talondo. Acuannya adalah besaran nilai rerata setiap subindeks berdasarkan variabel kelompok usia pada Tabel 6 yang kemudian divisualisasi dalam bentuk diagram jaring laba-laba (lihat Gambar 5).

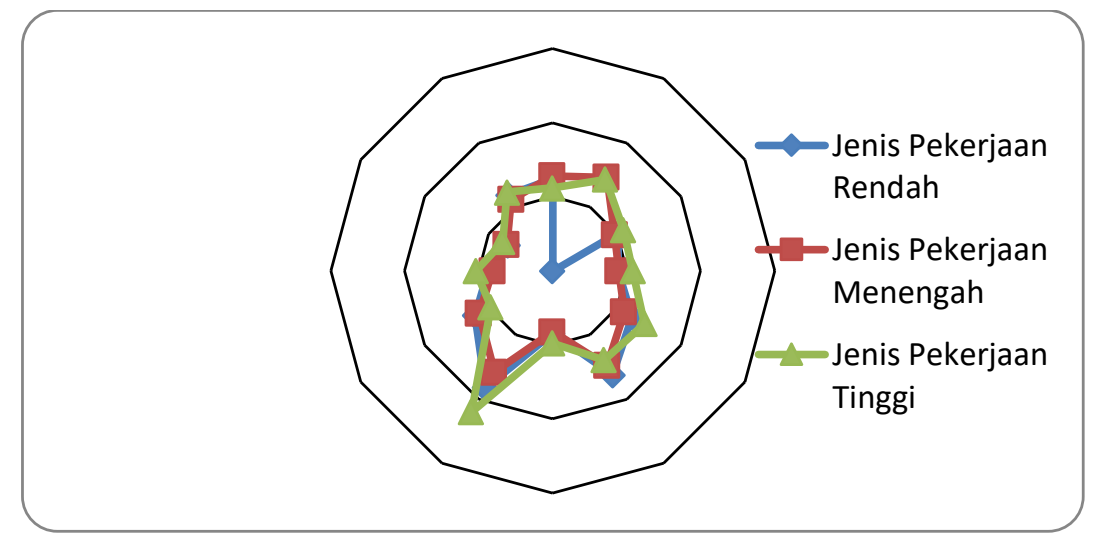

Gambar 5.

Rerata Antarindeks Berdasarkan Kategori Jenis Pekerjaan

Tabel 6.

Perbandingan Rerata Antarindeks Berdasarkan Kategori Jenis Pekerjaan

\begin{tabular}{|c|c|c|c|}
\hline \multirow{2}{*}{ Jenis Indeks } & \multicolumn{3}{|c|}{ Jenis Pekerjaan } \\
\hline & Rendah & Menengah & Tinggi \\
\hline Imob & 0,62 & 0,64 & 0,56 \\
\hline Ibil & 0,80 & 0,73 & 0,71 \\
\hline Itrn & 0,51 & 0,48 & 0,55 \\
\hline Ikel & 0,44 & 0,44 & 0,54 \\
\hline Isaksi & 0,62 & 0,56 & 0,72 \\
\hline Itulis & 0,81 & 0,74 & 0,69 \\
\hline Irasa & 0,42 & 0,41 & 0,49 \\
\hline Iagm & 0,91 & 0,79 & 1 \\
\hline Ipem & 0,60 & 0,58 & 0,48 \\
\hline Ipend & 0,43 & 0,41 & 0,52 \\
\hline Iskp & 0,35 & 0,36 & 0,39 \\
\hline Itotal & $\mathbf{0 , 5 9}$ & 0,56 & $\mathbf{0 , 6 1}$ \\
\hline
\end{tabular}

Sumber: Data Diolah dari Keluaran Tabel Compare Means dengan SPSS 19 
Perbandingan indeks total dan subindeks berdasarkan berdasarkan kelompok jenis pekerjaan (rendah, menengah, dan tinggi) pada Tabel 6 menunjukkan perbedaan. Secara total terlihat bahwa indeks vitalitas bahasa Talondo untuk kelompok yang berjenis pekerjaan rendah dan menengah terletak pada jaring/garis indeks ke- 3--4 dengan nilai indeks 0,59 dan 0.56 sehingga vitalitas bahasa Talondo untuk kedua kelompok jenis pekerjaan tersebut mengalami kemunduran. Tidak demikian halnya dengan yang berjenis pekerjaan tinggi karena indeks total vitalitas bahasa Talondo untuk kelompok ini berada pada garis 4--5 dengan nilai indeks 0,61 sehingga vitalitas bahasa Talondo untuk kelompok penutur yang berjenis pekerjaan tinggi tergolong stabil dan mantap, tetapi terancam punah.

Jika Tabel 3-6 pada uraian 4.2.1-4.2.4 ditelusuri, dapat diidentifikasi indeks total dan rata-rata indeks total pada masing-masing variabel (jenis kelamin, kelompok usia, jenjang pendidikan, dan jenis pekerjaan dengan subbagiannya). Retata indeks total variabel jenis kelamin dihasilkan sebesar 0,58, kelompok usia sebesar 0,59, jenjang pendidikan sebesar 0,58, dan jenis pekerjaan 0,59. Nilai-nilai tersebut belum dapat dijadikan sebagai penentu kriteria vitalitas bahasa Talondo karena ada dua kriteria yang muncul berdasarkan hubungan masing-masing karakteristik responden dengan ke-11 subindeks, yaitu mengalami kemunduran dan stabil dan mantap, tetapi terancam punah. Perhitungan itu masih secara mengarah pada perhitungan secara parsial. Oleh karena itu, perlu dicari alternatif perhitungan lain untuk menentukan kriteria vitalitas bahasa Talondo, yaitu secara gabungan/bersamasama. Cara seperti ini dapat dijadikan sebagai salah satu alternatif penentuan kriteria vitalitas bahasa termasuk bahasa Talondo. Dengan demikian, apabila dijumlahkah rerata indeks total keempat variabel dengan subbagiannya, hasilnya adalah 2,34. Dengan demikian, kriteria vitalitas bahasa Talondo masuk dalam kelompok mengalami kemunduran. Hal itu diperoleh dari perhitungan pembagian rerata indeks total keempat variabel dengan nilai 2,34 dengan empat variabel (jenis kelamin, kelompok usia, jenjang pendidikan, dan jenis pekerjaan dengan subbagiannya) sehingga nilai indeks didapatkan sebesar 0,58. Nilai itu masuk dalam garis indeks 3 - 4 pada diagram laba-laba dengan kriteria vitalitas bahasa mengalami kemunduran.

Tabel 7.

Retata Indeks Total Empat Variabel

\begin{tabular}{|c|c|}
\hline Jenis Variabel & Retata Indeks Total \\
\hline Jenis kelamin & 0,58 \\
\hline Kelompok usia & 0,59 \\
\hline Jenjang pendidikan & 0,58 \\
\hline Jenis pekerjaan & 0,59 \\
\hline Jumlah retata indeks total & 2,34 \\
\hline Rata-rata jumlah retata indeks total & $0,58+0,59+0,58+0,59=0,58$ \\
\hline
\end{tabular}




\section{SIMPULAN}

Rata-rata jumlah retata indeks total adalah 0,58. Nilai itu diperoleh dari perbandingan rerata antarindeks berdasarkan kategori jenis kelamin, kelompok usia, jenjang pendidikan, dan jenis pekerjaan. Dari hasil perbandingan itu diperoleh nilai masing-masing rerata indeks total karakteristik responden seperti jenis kelamin dengan rerata indeks total sebesar 0,58 , kelompok usia 0,59 , jenjang pendidikan 0,58 , dan jenis pekerjaan 0,59 . Itu berarti bahwa nilai retata indeks total sebesar 2,34. Dengan nilai retata indeks total sebesar 2,34 dibagi dengan keempat retata indeks total $(0,58+0,59+0,58+0,59)$ dihasilkan rata-rata jumlah retata indeks total sebesar 0,58. Dengan demikian, kriteria vitalitas bahasa Talondo digolongkan mengalami kemunduran dan masuk dalam garis indeks 3-4 berdasarkan visualiasinya dalam diagram laba-laba.

\section{DAFTAR PUSTAKA}

Coulmas, Florian, ed. (1997). The Handbokk of Sociolinguistics. Oxford: Blackwell. Crystal, David. (2000). Language Death. United Kingdom: Cambridge University Press.

Dixon, R.M.W. (1997). The Rise and Fall of Language. United Kingdom: Cambridge University Press.

Fishman, Joshua A. (1968). Reading in The Socciology of Language. The Hague \& Paris: Mouton.

Grimes, Barbara F. (2001). "Kecenderungan Bahasa untuk Hidup atau Mati secara Global, Sebab, Gejala, dan Pemulihan untuk Bahasa-Bahasa yang Terancam Punah". Dalam PELBBA 1--5. Jakarta: Pusat Kajian Bahasa dan Budaya Unika Atma Jaya. 24--25 Juli 2001.

. (2002). Global Language Viability: Causes, Symptoms, and Cures for Endangered Languages". [http:// www.sil.org/sociol/ndg-lg-indicators-html.]. Diakses 12 Juni 2016.

Ibrahim, A. Gufron. (2008). "Bahasa Terancam Punah: Sebab-sebab Gejala dan Strategi Pemecahannya". Dalam Kongres Internasional lX Bahasa Indonesia. Jakarta: Pusat Pembinaan dan Pengembangan Bahasa.

Mahsun, (2006). "Indigenisasi Bahasa Sumbawa di Lombok: Proses Adaptasi Menuju Pergeseran atau Pemertahanan Bahasa". Dalam Seminar Internasional Pelestarian Bahasa Daerah, Jakarta: Pusat Pembinaan dan Pengembangan Bahasa.

SIL. (2006). Bahasa-Bahasa di Indonesia. Jakarta: SIL International.

Sumarsono dan Partana Paina. (2004). Sosiolinguistik. Yogyakarta: Sabda 